\title{
A Prediction Model of Oil Cracked Gas Resources and Its Application in the Gas Pools of Feixianguan Formation in NE Sichuan Basin, SW China
}

\author{
Tongshan Wang, ${ }^{1}$ Ansng Geng, ${ }^{2}$ Xia Li, ${ }^{1}$ Hongjun Wang, ${ }^{1}$ Zecheng Wang, ${ }^{1}$ and Li Qiufen ${ }^{1}$ \\ ${ }^{1}$ Research Institute of Petroleum Exploration and Development, PetroChina, Beijing 100083, China \\ ${ }^{2}$ The State Key Laboratory of Organic Geochemistry, Guangzhou Institute of Geochemistry, Chinese Academy of Science, \\ Guangzhou 510640, China
}

Correspondence should be addressed to Tongshan Wang, wts2007@petrochina.com.cn

Received 30 September 2010; Revised 21 January 2011; Accepted 8 February 2011

Academic Editor: Vicki Hansen

Copyright (C) 2011 Tongshan Wang et al. This is an open access article distributed under the Creative Commons Attribution License, which permits unrestricted use, distribution, and reproduction in any medium, provided the original work is properly cited.

The prediction of oil cracked gas resources is necessary and urgent in the gas exploration of these basins at high to over stage in China. A marine crude oil sample was pyrolyzed using sealed gold tubes system in our study. The pyrolysates including gas, liquid, and solid were quantitatively analyzed. Based on the pyrolysis data and kinetic calculation, the yield correlativity among gas, liquid, and solid products was regressed with high correlative coefficients to establish a prediction model suitable for the resource estimation of oil cracked gas. The verification formula for this model was also established on the principle of mass conservation. The affecting factors and the application preconditions of this model were discussed. Finally the model was extrapolated to the prediction of oil cracked gas resources of Feixianguan formation in NE Sichuan basin, SW China. The prediction value of oil cracked resources is about $6.84 \times 10^{12} \mathrm{~m}^{3}$, and generation intensity of oil cracked gas is about $97.5 \times 10^{8} \mathrm{~m}^{3} / \mathrm{km}^{2}$, and the paleo-oil reserves is about $97 \times 10^{8}$ t. The verifying value for this prediction is approximately equal to 1 , indicating the model is reliable in the resource estimation of oil cracked gas.

\section{Introduction}

The presentation of oil cracked gas and the research of kinetic model of oil cracking have made contribution to the theory of natural gas generation [1-6]. It is shown that oil cracking is an important passway for gas generation from marine source rocks [7]. Oil cracked is a pyrolysis process to generate gaseous hydrocarbons and residues (solid bitumen) under certain temperature and pressure, which is similar to the generation of oil and gas from Kerogen. This process can be described by chemical kinetic equations. Kinetic pyrolysis experiment is an effective method to simulate it [8]. Natural gas should be mainly from oil cracked at the high-over mature stage of marine source rocks according to normal kinetic model [9]. The exploration of oil cracked gas may show a bright prospect because of the great thickness and wide distribution of marine sediment in China. It is important to predict resources of oil cracked gas accurately and effectively.

Conventional oil and gas resource assessment is normally based on the identification and evaluation of effective source rocks and the estimation of the potential of hydrocarbon generation $[10,11]$. However, it is difficult to draw reliable conclusions by applying traditional resource assessment parameters to the prediction of oil cracked gas resource since it is generally distributed in the lower part of superposition basins. The mechanism of the hydrocarbon distribution and accumulation in superposition basin is quite complicated [11], and the source rocks have evolved to high and over mature stage $[12,13]$. It is indicated in the exploration 
that the solid bitumen in reservoir in Sichuan Basin, Tarim Basin, and the extensive carbonate areas in south China is pyrobitumen formed in the process of oil cracked in paleooil reservoir $[14,15]$. The pyrobitumen is an important indicator of oil cracked gas. Meanwhile, it can be a new key to the resource assessment of oil cracked gas as an alternative of hydrocarbon source rock.

Previous studies on crude oil pyrolysis mainly focused on the mechanism of gas generation, the evolution of gaseous hydrocarbons and isotope composition [1-6, 8, 16, 17]. Less attention has been paid to the quantity changes of gas, liquid, and solid pyrolysates and the correlativity among them in pyrolysis. The correlation was not yet extrapolated to resource assessment at present.

In the process of oil pyrolysis in a closed system, it was noted that the yields of solid pyrobitumen and gaseous hydrocarbons continued to increase (a positive correlation between them), while the yield of liquid hydrocarbons decreased. Inspired from that, a prediction model for the resource assessment of oil cracked gas based on solid bitumen in reservoir was established according to the pyrolysis data and mass balance calculation [18]. Approach was provided for the estimation of natural gas resources and the restoration of paleo-oil accumulation in the areas with high-over mature marine source rocks in south China, furthermore, its application in the gas pools of Feixianguan formation is discussed here. It is significant for the decision-making of natural gas exploration in China.

\section{Sample and Experiment}

2.1. Sample. A normal marine crude oil sample was selected for pyrolysis experiment from Ordovician interior reservoirs in the depth of 5940-5983 m in Well YM2 in Tarim Basin. The oil sample contains $47.3 \%$ saturates, $26.4 \%$ aromatics, $13 \%$ nonhydrocarbons, and $5.95 \%$ asphaltenes. The ratio of saturates to aromatics is 1.79 .

2.2. Experiment. Oil cracked generally occurred in a relatively closed paleo-oil reservoir in geological condition, so a pressurized confined gold tube system was adopted in our experiment. The equipment and principle were presented elsewhere in detail $[12,17,19]$. Here the experimental procedures are briefly described as follows. The prepared oil sample (5-40 mg) was sealed in gold tubes $(40 \mathrm{~mm} \times 4.2 \mathrm{~mm}$ i.d.) and charged with argon. All of the gold tubes were placed in stainless steel autoclaves quickly placed in the oven. The pressure of autoclaves was kept at $50 \mathrm{MPa}$. The temperature were programmed to increase at a rate of $2^{\circ} \mathrm{C} / \mathrm{h}$ and $20^{\circ} \mathrm{C} / \mathrm{h}$, respectively, from $350^{\circ} \mathrm{C}$ to $600^{\circ} \mathrm{C}$. For each of the two heating series, oil samples were loaded into gold tubes under anhydrous conditions. All autoclaves were heated in a uniform oven. At last, the autoclaves were removed from the oven one by one and then quenched in a cold water bath when the desired temperatures were reached. During the experimental heating process, the temperature error is less than $1^{\circ} \mathrm{C}$, and the pressure error is less than $5 \mathrm{MPa}$.
2.2.1. Gas Analysis. Cleaned gold tubes were placed in a vacuum line connected to an Agilent $6890 \mathrm{~N}$ gas chromatography. After isolating the extraction line from the vacuum pump, the tube was pierced with a needle, allowing the gas to be volatilized into the line. Then, molecular characterization and quantification of the total gas fraction were performed by gas chromatography. External standard method was applied to the quantification of gas components. The GC conditions were as follows. The column was kept at $40^{\circ} \mathrm{C}$ for $6 \mathrm{~min}$, programmed to $180^{\circ} \mathrm{C}$ at a rate of $25^{\circ} \mathrm{C} / \mathrm{min}$, and finally kept at $180^{\circ} \mathrm{C}$ for $4 \mathrm{~min}$.

Residual liquid hydrocarbons comprise light hydrocarbons $\left(\mathrm{C}_{6}-\mathrm{C}_{13}\right)$ and heavy hydrocarbons $\left(\mathrm{C}_{13+}\right)$. Following gas analysis, the light hydrocarbons were frozen in a vial $(4 \mathrm{~mL})$ by liquid nitrogen and quickly added into pentane solution. The punctured gold tubes were removed from the vacuum device, cut open, and added to the vial. Then it was extracted three times by sonication in pentane and taken out. The internal standard of deuterated-nC18 was added into the solution in vial which was placed for hours after constant volume. A part of the solution $(200 \mu \mathrm{L})$ was taken out for the quantitative analysis of light hydrocarbons. The remaining part was filtered using repeated washing with dichloromethane. The filtrates were evaporated and weighted. The $\mathrm{C}_{13+}$ fraction was then measured. The light hydrocarbons analysis was carried out by Finnigan Trace GC Ultra gas chromatography and Quadax column $(50 \mathrm{~m} \times 0.25 \mathrm{~mm})$. The GC conditions were as follows. The column was kept at $40^{\circ} \mathrm{C}$ for $6 \mathrm{~min}$, programmed to $180^{\circ} \mathrm{C}$ at a rate of $25^{\circ} \mathrm{C} / \mathrm{min}$, and finally kept at $180^{\circ} \mathrm{C}$ for $4 \mathrm{~min}$.

Residual liquid hydrocarbons comprise light hydrocarbons $\left(\mathrm{C}_{6}-\mathrm{C}_{13}\right)$ and heavy hydrocarbons $\left(\mathrm{C}_{13+}\right)$. Following gas analysis, the light hydrocarbons were frozen in a vial $(4 \mathrm{~mL})$ by liquid nitrogen and quickly added into pentane solution. The punctured gold tubes were removed from the vacuum device, cut open, and added to the vial. Then it was extracted three times by sonication in pentane and taken out. The internal standard of deuterated-nC18 was added into the solution in vial which was placed for hours after constant volume. A part of the solution $(200 \mu \mathrm{L})$ was taken out for the quantitative analysis of light hydrocarbons. The remaining part was filtered by dichloromethane again and again. The filtrates were evaporated and weighted. The $\mathrm{C}_{13+}$ fraction then can be measured. The light hydrocarbons analysis was carried out by Finnigan Trace GC Ultra gas chromatography and Quadax column $(50 \mathrm{~m} \times 0.25 \mathrm{~mm})$. The GC conditions were as follows: the column was kept at $50^{\circ} \mathrm{C}$ for $2 \mathrm{~min}$, programmed to $290^{\circ} \mathrm{C}$ at a rate of $4^{\circ} \mathrm{C} / \mathrm{min}$, and finally kept at $290^{\circ} \mathrm{C}$ for $30 \mathrm{~min}$. Thus, the total $\mathrm{C}_{6-13}$ fraction can be accurately measured.

Organic filter papers $(0.45 \mu \mathrm{m} \times 25 \mathrm{~mm})$ were used to recover the pyrobitumen. Each of the filter papers was weighed beforehand. After being filtered, the filter papers together with pyrobitumen were dried and weighed again to determine the amount of pyrobitumen. All these operations were done in the same experimental condition (temperature $20^{\circ} \mathrm{C}$; humidity $45 \%$ ) and with the same electric balance (systematical error no more than $0.003 \mathrm{mg}$ ) to minimize experimental errors. 


\section{Results and Discussion}

3.1. Changes in the Yields of Gas, Liquid, and Solid Pyrolysates. The total gaseous products, residual liquid hydrocarbon, and pyrobitumen generated from pyrolysis are discussed here. The volume and the quality of total gaseous products are the sum of $\mathrm{C}_{1-5}$ plus $\mathrm{H}_{2}$ and $\mathrm{CO}_{2}$, and so forth. The quality of the residual liquid hydrocarbon is the sum of $\mathrm{C}_{6-13}$ and $\mathrm{C}_{13+}$.

The yields of total gas (volume yield) and pyrobitumen increase continuously along with the rise of pyrolysis temperature (the two yield curves resemble each other), while the yield of residual liquid hydrocarbon decreases (Figure 1 and Table 1).

At the heating rate of $2^{\circ} \mathrm{C} / \mathrm{h}$, crude oil cracked began at about $380^{\circ} \mathrm{C}$ with low yields of total gas volume $(20 \mathrm{~mL} / \mathrm{g})$ and pyrobitumen $(9 \mathrm{mg} / \mathrm{g})$. The two yields increased quickly to $684 \mathrm{~mL} / \mathrm{g}$ and $335 \mathrm{mg} / \mathrm{g}$, respectively, from $420^{\circ} \mathrm{C}$ to $500^{\circ} \mathrm{C}$ and then slowly increased above $500^{\circ} \mathrm{C}$. It reached the maximum value $(796 \mathrm{~mL} / \mathrm{g}, 429 \mathrm{mg} / \mathrm{g})$, respectively, by $600^{\circ} \mathrm{C}$. By contrast, the yield of residual liquid hydrocarbons decreased quickly to $54 \mathrm{mg} / \mathrm{g}$ below $500^{\circ} \mathrm{C}$ and then went slowly to a value of zero. The result implies that the oil cracked process could be divided into two stages with possibly different mechanisms.

As shown in Figure 1, the change trends of the yield curves of all pyrolysates under two heating rates are similar. The yields under the low heating rate $\left(2^{\circ} \mathrm{C} / \mathrm{h}\right)$ lag behind those under the high heating rate $\left(20^{\circ} \mathrm{C} / \mathrm{h}\right)$. It indicates that a compensation relationship exists between time and temperature during the chemical process of oil pyrolysis [20].

A software for kinetic analysis was utilized for the data processing in order to eliminate the influence upon the oil pyrolysis experiment under different heating rates and discuss the characteristics in different evolution phases of oil cracked. The method showing thermal maturity expressed as equivalent vitrinite reflectance $\left(\% R_{o}\right)$ by Sweeney was adopted [21]. The experimental data and the kinetic parameters from [21] are processed with the software for kinetic analysis. The $F$ corresponding to different temperatures can be derived. The Easy\% $R_{o}$ value corresponding to different temperatures can be derived according to the formula: Easy $\% R_{o}=\operatorname{EXP}(-1.6+3.7 F)$. Then the changes in the yields of crude oil pyrolysates along with Easy\% $R_{o}$ (Figure 2) can be established. As shown in Figure 2, the trend of yield curves based on kinetic calculation data is approximately consistent with that derived from experimental data. The influence under different heating rates is so unconspicuous that the yield curves under different heating rates almost overlap each other. The yields of gas and pyrobitumen increase, whereas liquid hydrocarbons yield decreases quickly at about Easy $\% R_{0} 0.8 \%-1.6 \%$. All the yield curves extend gently as far as Easy $\% R_{o}$ 4.4. The ultimate pyrolysates are methane and coke residue [8].

3.2. Yield Correlativity among Gas, Liquid, and Solid Pyrolysates. The increase or decrease of gas, liquid, and solid matter in the process of oil cracked can be shown as the correlativity among the three yields. Based on the kinetic calculation and experimental data, the correlativity

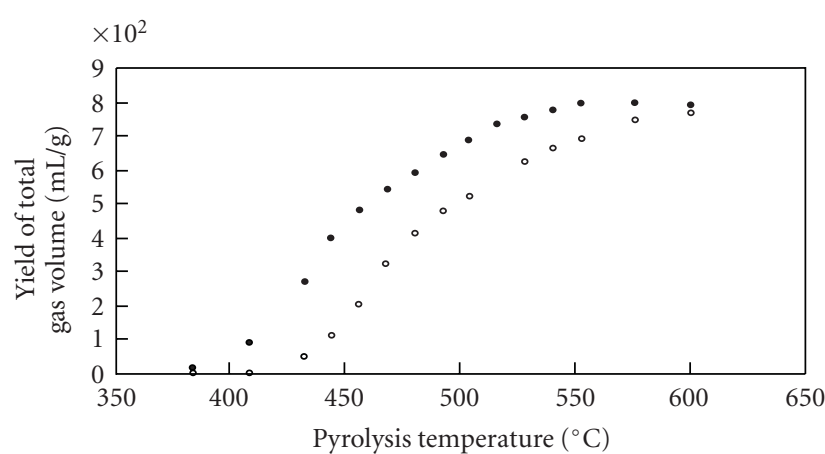

(a)

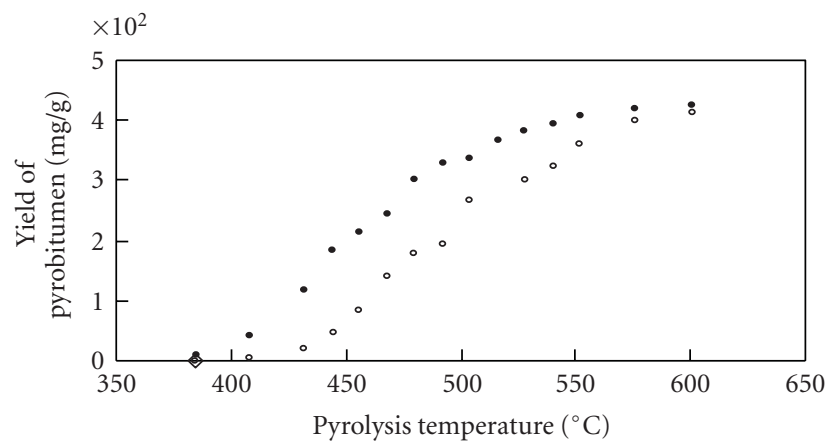

(b)

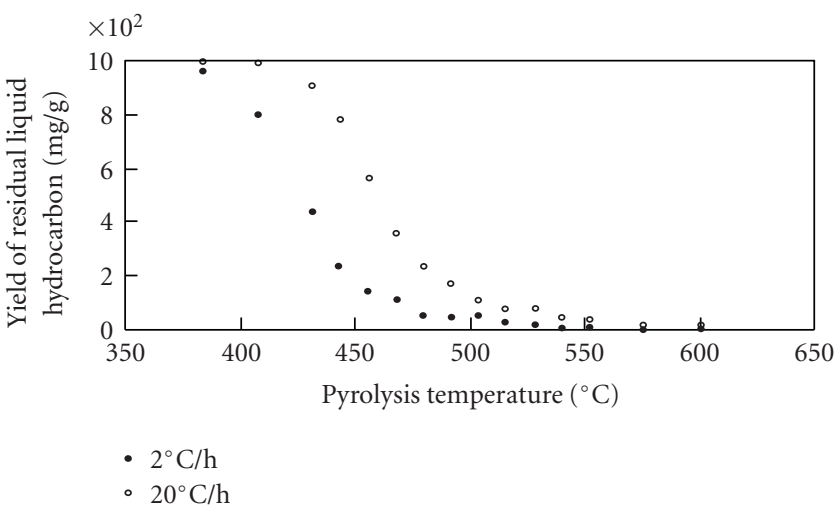

(c)

FIGURE 1: Changes in the yields of crude oil pyrolysates along with pyrolysis temperature.

among the yields of total gas volume and residual liquid hydrocarbons as well as solid pyrobitumen was regressed with high correlative coefficients in this study (Figure 3).

There is linear positive correlativity between the yields of total gas volume and pyrobitumen (Figure 3(a)). It indicates that the two yields increase continuously and simultaneously. In other words, when an amount of pyrobitumen was generated from crude oil pyrolysis, a corresponding volume of gas was generated. The rate of the two yields should be close to a constant (slope in the liner formula). The yield correlativity (quadratic function) between pyrobitumen and residual liquid hydrocarbons resemble that between total gas volume and residual liquid hydrocarbons (Figures 3(b) and $3(\mathrm{c}))$. It indicates that the residual liquid hydrocarbons decreased (ultimately with only traces left) following 
TABLE 1: Gas composition yields of crude oil pyrolysates along with pyrolysis temperature.

\begin{tabular}{|c|c|c|c|c|c|c|c|}
\hline \multirow{2}{*}{ Heating rate ${ }^{\circ} \mathrm{C} / \mathrm{h}$} & \multirow{2}{*}{ Temperature ${ }^{\circ} \mathrm{C}$} & \multicolumn{6}{|c|}{ Composition of natural gas (\%) } \\
\hline & & $\mathrm{CH}_{4}$ & $\mathrm{C}_{2} \mathrm{H}_{6}$ & $\mathrm{C}_{3} \mathrm{H}_{8}$ & $\mathrm{C}_{4} \mathrm{H}_{10}$ & $\mathrm{H}_{2}$ & $\mathrm{CO}_{2}$ \\
\hline \multirow{9}{*}{20} & 408 & 3.97 & 1.78 & 1.45 & 0.72 & 0.59 & 0.71 \\
\hline & 444 & 37.86 & 26.33 & 25.14 & 14.58 & 1.53 & 2.64 \\
\hline & 456 & 58.77 & 44.77 & 46.71 & 35.39 & 1.98 & 1.23 \\
\hline & 492 & 208.22 & 128.92 & 92.45 & 40.70 & 4.32 & 1.67 \\
\hline & 504 & 257.90 & 141.56 & 86.70 & 27.77 & 4.82 & 1.98 \\
\hline & 540 & 470.16 & 149.03 & 34.79 & 4.33 & 6.75 & 1.71 \\
\hline & 552 & 527.00 & 132.27 & 17.09 & 1.82 & 7.66 & 6.63 \\
\hline & 576 & 641.08 & 90.63 & 2.83 & 0.29 & 11.23 & 2.04 \\
\hline & 600 & 702.07 & 52.49 & 1.04 & 0.07 & 14.61 & 2.42 \\
\hline \multirow{9}{*}{2} & 408 & 28.60 & 16.17 & 20.26 & 17.34 & 0.93 & 0.94 \\
\hline & 444 & 145.24 & 95.10 & 84.12 & 51.02 & 2.50 & 1.71 \\
\hline & 456 & 205.61 & 124.24 & 93.89 & 44.67 & 3.21 & 3.84 \\
\hline & 492 & 430.56 & 151.56 & 46.57 & 6.60 & 4.96 & 4.06 \\
\hline & 504 & 504.74 & 142.72 & 25.41 & 2.97 & 5.54 & 2.52 \\
\hline & 540 & 684.73 & 74.88 & 1.67 & 0.17 & 9.81 & 3.20 \\
\hline & 552 & 724.01 & 53.93 & 0.98 & 0.08 & 10.67 & 7.20 \\
\hline & 576 & 765.77 & 16.66 & 0.28 & 0.00 & 11.20 & 2.54 \\
\hline & 600 & 770.98 & 4.62 & 0.09 & 0.00 & 11.40 & 4.50 \\
\hline
\end{tabular}

a quadratic function with the increase of the total gas volume and pyrobitumen. It is important to point out that the regressed correlation formula only can be applied within certain limits and the values of variable in the formula are not more than the maximum yield of all kinds of pyrolysates. Furthermore, Figure 3 shows that there is little difference between the constant coefficients in the correlation formula regressed from kinetic calculation and that from experimental data. It indicates that the correlation formula is reliable in theory.

3.3. Mass Conservation in the Process of Crude Oil Pyrolysis. The total quality was conserved in the process of oil pyrolysis, no matter how gas, liquid, and solid pyrolysates changed, respectively, in quality because a confined pyrolysis system close to the geological conditions of the plaeo-oil in reservoir cracked was adopted. At any time, the sum of the quality yields of all pyrolysates should be equal or approximately equal to 1 . The volume yield of gas is converted to quality yield according to the composition of gaseous pyrolysates. The mass conservation is discussed through the changes in quality of gas, liquid, and solid pyrolysates in the process of oil pyrolysis (Figure 4).

At the beginning of oil pyrolysis, the quality of total gas and pyrobitumen increased continuously until the quality percentage of total gas went up to $65 \%$ where an inflexion appeared (Figure $4(\mathrm{a})$ ). Then the quality of total gas began to decrease but the quality of pyrobitumen increased continuously. The quality percentage of the ultimate pyrolysates was $55 \%$ total gas and $45 \%$ pyrobitumen. In the later period of oil pyrolysis, the $\mathrm{C}_{2-5}$ gas hydrocarbons cracked continuously to methane and pyrobitumen, and the percentage of methane in pyrolysates increased. Although the volume of total gas continued to increase, the quality reduced at the same time. The quality reduction of total gas was transferred to pyrobitumen. The quality yield curves of gas, liquid, and solid pyrolysates based on kinetic calculation data under the two heating rates coincided with each other approximately (Figure $4(\mathrm{~b})$ ). The curves a and $a^{\prime}$ (quality yield of total gas) began to descend gently (from 0.65 to ultimate value 0.55 ) at around over 2.0 of Easy $\% R_{o}$ where an inflexion appeared. The quality yield curves of pyrobitumen ( $c$ and $\left.c^{\prime}\right)$ and residual liquid hydrocarbons $\left(b\right.$ and $\left.b^{\prime}\right)$ show the same change trend with that shown in Figure 2 . The value of mass balance curves ( $d$ and $d^{\prime}$ ) was close to 1 all the while. It indicates that the total quality is approximately constant in oil pyrolysis in confined system. Therefore, at any value of Easy $\% R_{o}$ the relationships $d=a+b+c$ and $d^{\prime}=a^{\prime}+b^{\prime}+c^{\prime}$ exist. The values of $d$ and $d^{\prime}$ are equal or approximately equal to 1 . It not only proves the mass conservation in the process of crude oil pyrolysis, but also certifies the yield correlation among gas, liquid, and solid pyrolysates.

\section{Prediction Model of Oil Cracked Gas Resources}

4.1. Establishment of the Prediction Model. As shown by the correlativity formulas regressed in Figure 3, the increase or decrease of gas, liquid, and solid products in the process of oil pyrolysis in confined system can be expressed by formulas with variables. If the value of quantity or yield of any phase pyrolysates is given, the values of the other two phases can be got. The correlation can be extrapolated to practical geological conditions. If the quality of solid bitumen in reservoir is given, the resources of the corresponding 


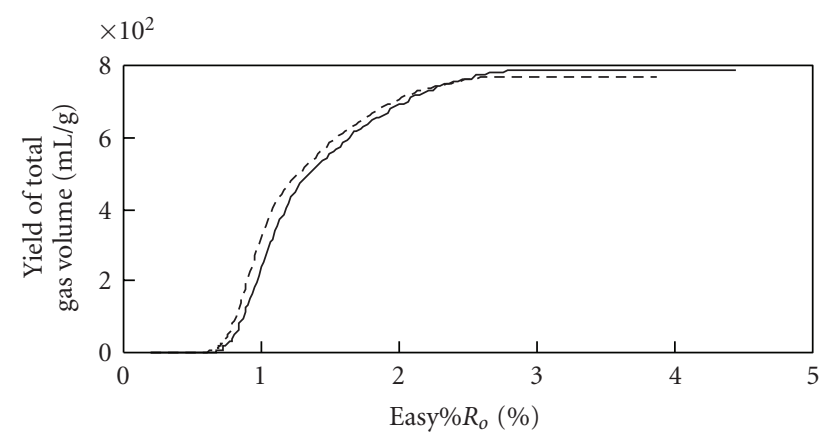

(a)

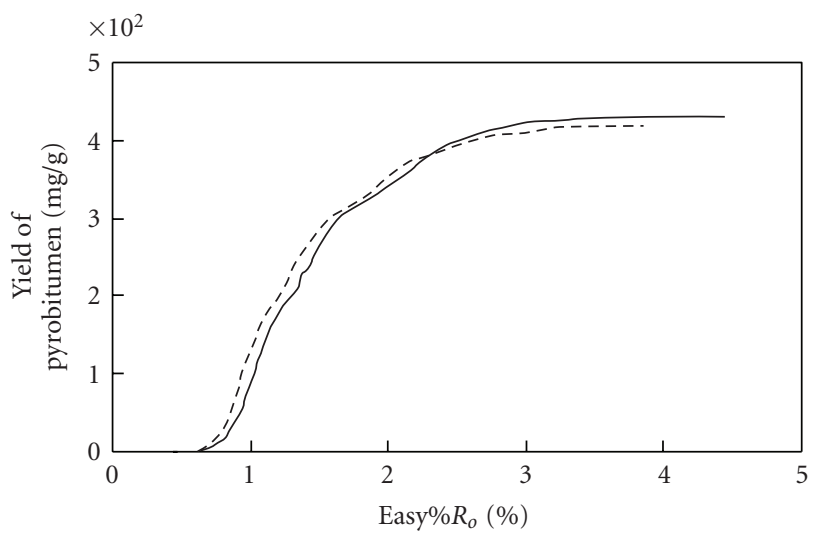

(b)

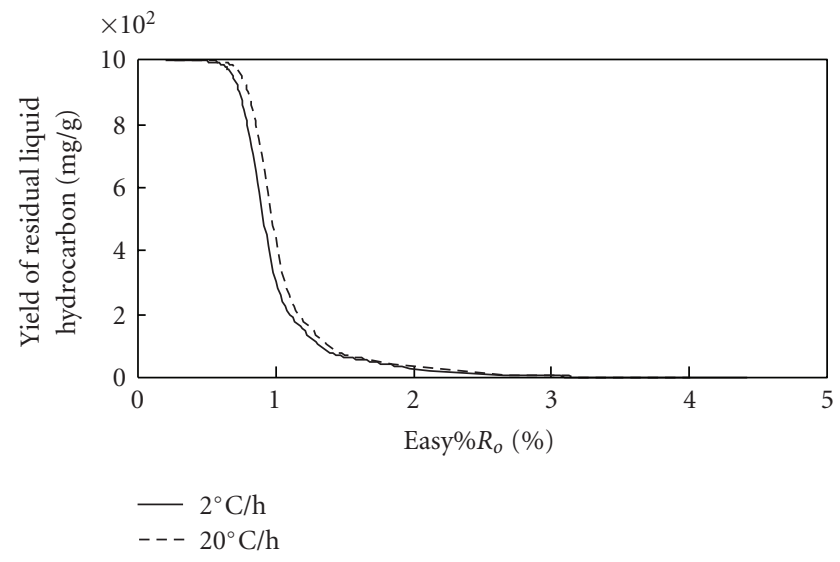

(c)

FIGURe 2: Changes in the yields of crude oil pyrolysates along with Easy\% $R_{o}$.

natural gas (oil cracked) and paleo-oil in reservoir can be determined. Therefore, a prediction model for the resource estimation of oil cracked gas is established here. The variables in the model are listed in Table 2.

The influence exerted by two different heating rates and the errors in pyrolysis can be eliminated by kinetic calculation. The results of that can be extrapolated to geological application. Therefore, the formulas regressed by kinetic calculation data in Figure 3 are adopted to express the yield correlation among gas, liquid, and solid pyrolysates in oil pyrolysis. The variables in Table 1 are substituted into them to get the formulas as follows:

$$
\begin{aligned}
C v_{g} & =1.8095 C_{b}+47.226, \\
C_{L} & =0.0079\left(C_{b}\right)^{2}-5.5598 C_{b}+964.14, \\
C_{L} & =0.0017\left(C v_{g}\right)^{2}-2.6037 C v_{g}+989.71,
\end{aligned}
$$

where $C v_{g}=v_{g} / m_{o}, C_{b}=m_{b} / m_{o}, C_{L}=m_{L} / m_{o}, C m_{g}=$ $m_{g} / m_{o}$.

Since the cracking of the paleo-oil in reservoir occurred in a closed geological system, mass conservation should exist in oil pyrolysis. The relevant variables in Table 1 are put into the expression of mass conservation in Figure 4(b) to get the verification formula as follows:

$$
\text { Verification formula } C m_{\mathrm{g}}+C_{\mathrm{b}}+C_{\mathrm{L}}=1 \text {. }
$$

According to the natural gas resources (volume) derived from prediction model and its composition from GC analysis, the quality of natural gas can be calculated out and put into formula (2). If the sums are equal or approximately equal to 1 , the prediction value of natural gas resources would be reliable in theory.

4.2. Factors Influencing of the Prediction Model. Because the prediction model is established based on the pyrolysis result of only one crude oil sample, some influence factors may exist as follows.

(1) Property of Crude Oil. The cracking of crude oil with different properties (such as percentage of saturates, aromatics, nonhydrocarbons, and asphaltenes) may produce different yields (such as gas or pyrobitumen). For example, if a heavy crude oil with high asphaltenes cracked, the pyrobitumen yield will be high, and the quality proportion of the ultimate products (methane and coke) will be different from that of normal crude oil. Moreover, the special elements content (such as sulfur), viscosity, density and other properties of crude oil will also affect the rate of cracking and the yield of pyrolysates.

(2) Measurement Errors in Experiment. Measurement errors have direct impact on the results of oil pyrolysis. For example, the factors such as the weight and water absorption of the filters will make the quantitative value higher or lower in the course of determining the amount of pyrobitumen. If the filter papers are not washed clearly by dichloromethane, the macromolecular asphaltenes retained on the filter paper will make the quantitative value of pyrobitumen higher. In addition, the volatilization of gas and light hydrocarbons will make the quality value of residual liquid hydrocarbons and gas volume lower.

(3) Some secondary alterations of the natural gas or oil could produce an effect on the sensitivity of prediction model, such as TSR [24, 25] and the interaction between the minerals of reservoir rocks and crude oil. 

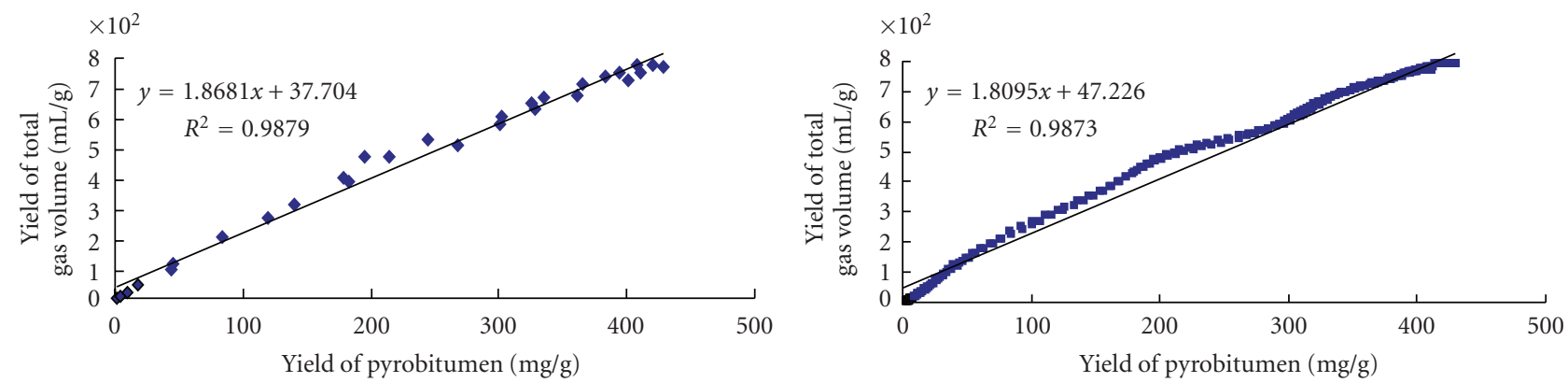

(a) The correlation between the yields of pyrobitumen and total gas volume (Left: pyrolysis data; Right: Kinetic calculation data)
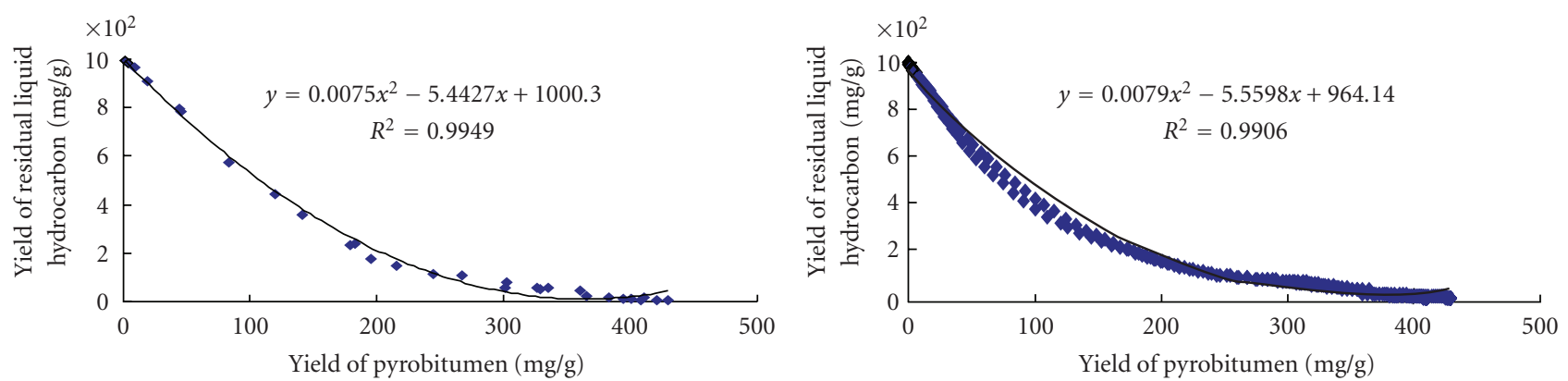

(b) The correlation between the yields of pyrobitumen and residual liquid hydrocarbon (Left: pyrolysis data; Right: kinetic calculation data)
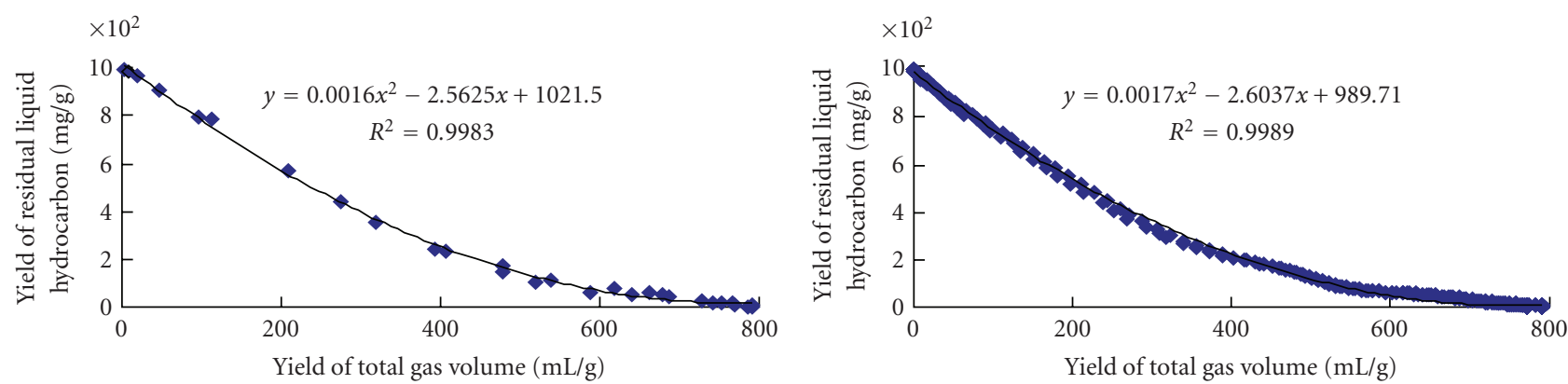

(c) The correlation between the yields of total gas volume and residual liquid hydrocarbon (Left: pyrolysis data; Right: kinetic calculation data)

Figure 3: Correlation of the yields among gas, liquid, and solid pyrolysates in oil pyrolysis. (a) The correlation between the yields of pyrobitumen and total gas volume (Left: pyrolysis data; Right: Kinetic calculation data); (b) the correlation between the yields of pyrobitumen and residual liquid hydrocarbon (Left: pyrolysis data; Right: kinetic calculation data); (c) the correlation between the yields of total gas volume and residual liquid hydrocarbon (Left: pyrolysis data; Right: kinetic calculation data).

However, the factors described above affect only the value of products yield. It cannot change the rules in pyrolysis. Perhaps, the value of constant coefficient in the correlativity formulas of prediction model can fluctuate a little because of these factors, but the linearity and quadratic function maintain.

4.3. Application Preconditions of the Prediction Model. The resources of oil cracked gas can be predicted effectively using this model with the advantages as follows. Resource evaluation can be taken according to solid bitumen in reservoir instead of source rocks; the restoring of hydrocarbon potential and the evaluation of high mature source rocks are avoided. However, the model may not be suitable for the prediction of resources of all kinds of natural gas accumulations. Some preconditions should be met with in practice. (1) The most important application precondition is that the natural gas should be generated from oil cracking. For the
TABLE 2: Variables in the prediction of oil cracked gas resources.

\begin{tabular}{lcc}
\hline Variables & Symbol & Unit \\
\hline Resources of paleo-oil in reservoir & $m_{o}$ & $\mathrm{~g}$ \\
Volume of natural gas & $v_{g}$ & $\mathrm{~mL}$ \\
Quality of natural gas & $m_{g}$ & $\mathrm{mg}$ \\
Quality of solid bitumen in reservoir & $m_{b}$ & $\mathrm{mg}$ \\
Quality of residual liquid hydrocarbon & $m_{L}$ & $\mathrm{mg}$ \\
Volume yield of natural gas & $C v_{g}$ & $\mathrm{~mL} / \mathrm{g}$ \\
Quality yield of natural gas & $C m_{g}$ & $\mathrm{mg} / \mathrm{g}$ \\
Yield of solid bitumen in reservoir & $C_{b}$ & $\mathrm{mg} / \mathrm{g}$ \\
Yield of residual liquid hydrocarbon & $C_{L}$ & $\mathrm{mg} / \mathrm{g}$ \\
\hline
\end{tabular}

gas accumulations dominated by oil cracking but mixed with gas from other origins, the prediction value by this model will be lower than the factual value. (2) The generation, 


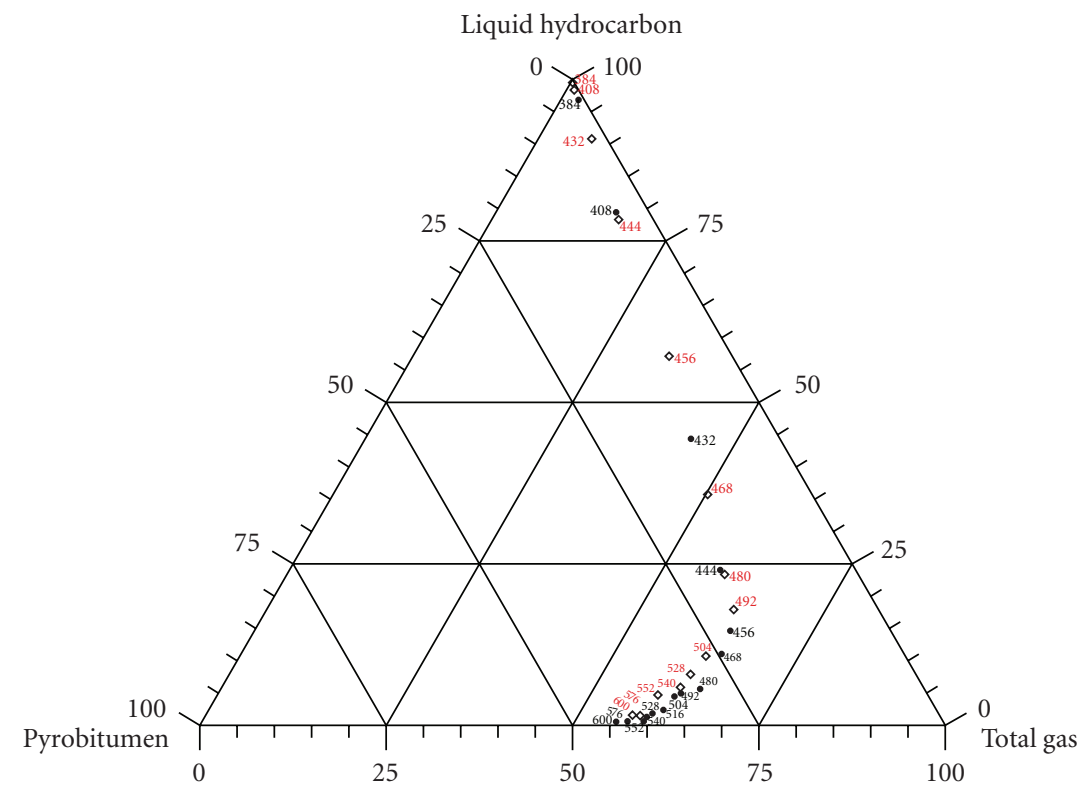

$504 \diamond 20^{\circ} \mathrm{C} / \mathrm{h}$

$480 \cdot 2^{\circ} \mathrm{C} / \mathrm{h}$

(a) Triangular diagram for the changes in quality percentage of gas, liquid, and solid pyrolysates in crude oil pyrolysis (pyrolysis data)

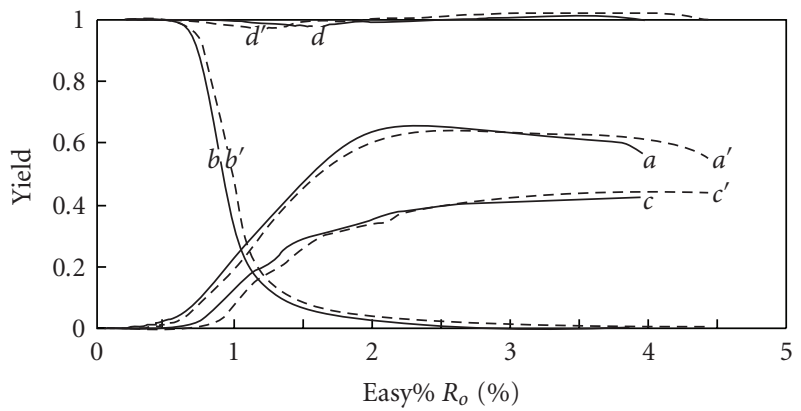

$-20^{\circ} \mathrm{C} / \mathrm{h}$

$a$-quality yield of total gas $20^{\circ} \mathrm{C} / \mathrm{h}, b$-quality yield of residual liquid hydrocarbon $20^{\circ} \mathrm{C} / \mathrm{h}$, c-quality yield of pyrobitumen $20^{\circ} \mathrm{C} / \mathrm{h}$

$a^{\prime}$-quality yield of total gas $2^{\circ} \mathrm{C} / \mathrm{h}, b^{\prime}$-quality yield of residual liquid hydrocarbon $2^{\circ} \mathrm{C} / \mathrm{h}, \mathrm{c}^{\prime}$-quality yield of pyrobitumen $2^{\circ} \mathrm{C} / \mathrm{h}$

$d$-quanlity balance curve $20^{\circ} \mathrm{C} / \mathrm{h}$, at any time $d=a+b+c \approx 1$

$d^{\prime}$-quanlity balance curve $2^{\circ} \mathrm{C} / \mathrm{h}$, at any time $d^{\prime}=a^{\prime}+b^{\prime}+c^{\prime} \approx 1$

(b) Curves of the quality yield of gas, liquid, and solid pyrolysates in crude oil pyrolysis (kinetic calculation data)

FIGURE 4: Mass conservation in the process of crude oil pyrolysis. (a) Triangular diagram for the changes in quality percentage of gas, liquid, and solid pyrolysates in crude oil pyrolysis (pyrolysis data); (b) curves of the quality yield of gas, liquid, and solid pyrolysates in crude oil pyrolysis (kinetic calculation data). $a$ : Quality yield of total gas $20^{\circ} \mathrm{C} / \mathrm{h} ; b$ : quality yield of residual liquid hydrocarbon $20^{\circ} \mathrm{C} / \mathrm{h} ; c$ : quality yield of pyrobitumen $20^{\circ} \mathrm{C} / \mathrm{h} ; a^{\prime}$ : quality yield of total gas $2^{\circ} \mathrm{C} / \mathrm{h} ; b^{\prime}$ : quality yield of residual liquid hydrocarbon $2^{\circ} \mathrm{C} / \mathrm{h} ; c^{\prime}$ : quality yield of pyrobitumen $2^{\circ} \mathrm{C} / \mathrm{h} ; d$ : quality balance curve $20^{\circ} \mathrm{C} / \mathrm{h}$, at any time $d=a+b+c \approx 1 ; d^{\prime}$ : quality balance curve $2^{\circ} \mathrm{C} / \mathrm{h}$, at any time $d^{\prime}=a^{\prime}+b^{\prime}+c^{\prime} \approx 1$

accumulation, and preservation of oil cracked gas should occur in a relatively closed geological system. In other words, tectonic activities did not bring large destruction on the accumulations when oil is being cracked or after gas accumulated. Meanwhile, the natural gas resources lost little in the process of accumulation. Otherwise, the prediction value by this model will be higher than the factual value of the resources of present gas accumulations.

\section{A Case of Geological Application}

This model was extraporlated to the oil cracked gas pools of Feixianguan Formation in NE Sichuan basin to verify the reliability and practicability of the prediction model.

5.1. Geological Setting. The NE Sichuan Basin was part of a carbonate platform during the Feixianguan 

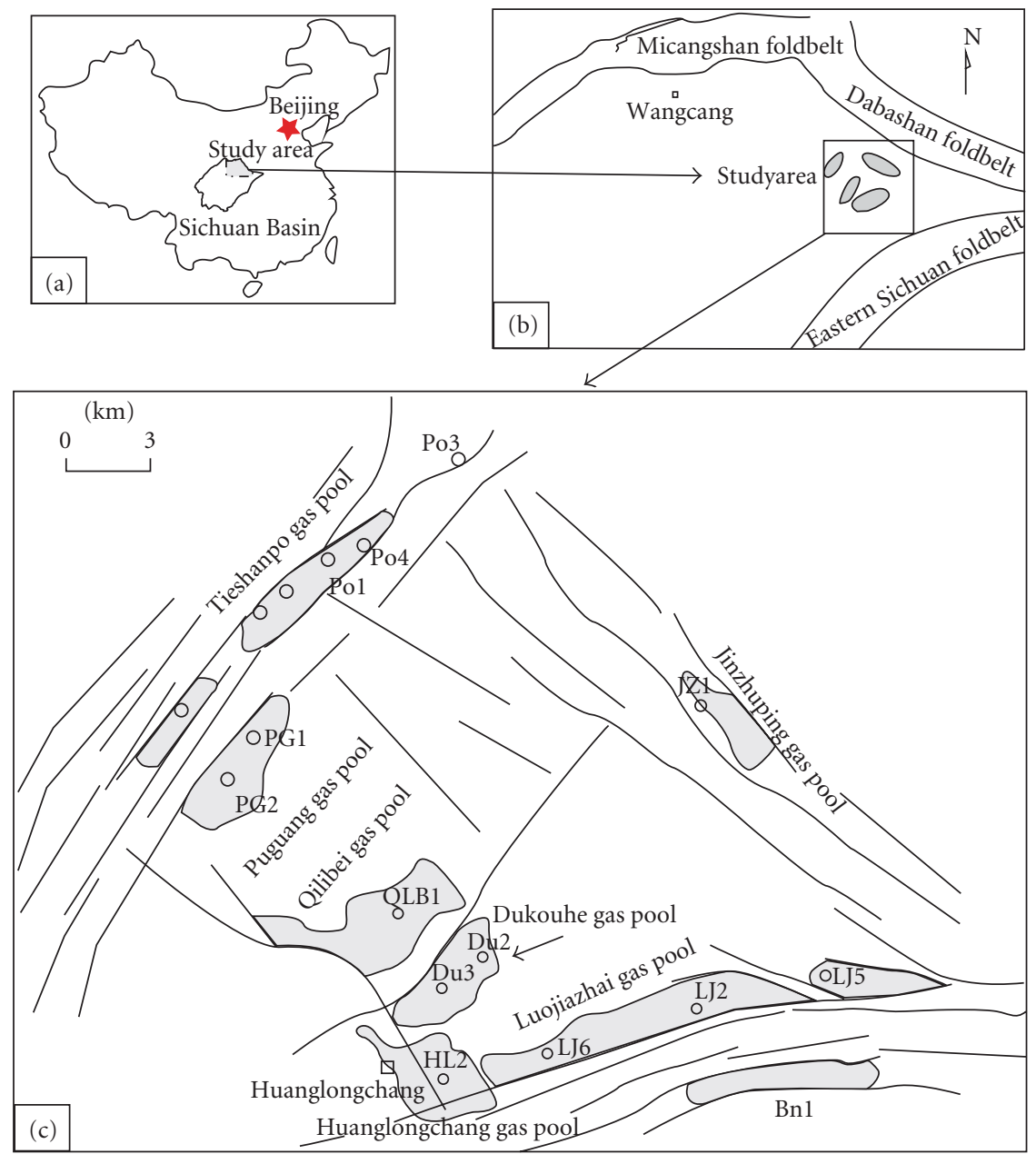

OLJ5 Well

Gas pool

$\triangle$ Fault

Figure 5: Maps showing location of study area (a, b) and distribution of gas pools (b) (modified from [22, 23]).

TABLE 3: Natural gas composition of Feixianguan Formation gas pools in NE Sichuan.

\begin{tabular}{|c|c|c|c|c|c|c|c|c|}
\hline \multirow{2}{*}{ Well } & \multicolumn{8}{|c|}{ Composition of natural gas (\%) } \\
\hline & $\mathrm{CH}_{4}$ & $\mathrm{C}_{2} \mathrm{H}_{6}$ & $\mathrm{C}_{3} \mathrm{H}_{8}$ & $\mathrm{H}_{2} \mathrm{~S}$ & $\mathrm{CO}_{2}$ & $\mathrm{~N}_{2}$ & $\mathrm{H}_{2}$ & $\mathrm{He}$ \\
\hline$\overline{\text { Dul }}$ & 82.70 & 0.04 & 0.04 & 16.21 & 0.46 & 0.42 & 0.1 & 0.014 \\
\hline Du2 & 78.74 & 0.04 & 0.01 & 16.24 & 3.29 & 1.6 & - & - \\
\hline Du3 & 73.71 & 0.06 & 0.05 & 17.06 & 8.27 & 0.79 & 0.0 & 0.014 \\
\hline Du4 & 83.73 & 0.06 & 0.00 & 9.81 & 5.03 & 0.65 & 0.7 & 0.015 \\
\hline Po1 & 78.38 & 0.05 & 0.02 & 14.19 & 6.36 & 0.92 & 0.0 & 0.023 \\
\hline Po2 & 80.79 & 0.03 & 0.03 & 10.59 & 7.22 & 0.98 & 0.0 & 0.023 \\
\hline Po4 & 76.90 & 0.04 & 0.0 & 14.2 & 7.62 & 0.95 & 0.278 & 0.015 \\
\hline LJ1 & 75.29 & 0.11 & 0.06 & 10.49 & 10.41 & 0.18 & 3.447 & 0.013 \\
\hline LJ2 & 84.68 & 0.08 & 0.03 & 8.77 & 5.44 & 0.71 & 0.274 & 0.017 \\
\hline LJ4 & 84.5 & 0.08 & 0.0 & 7.13 & 5.13 & 0.56 & 2.587 & 0.018 \\
\hline LJ5 & 76.66 & 0.05 & 0.0 & 13.74 & 8.93 & 0.59 & 0.008 & 0.023 \\
\hline LJ6 & 84.95 & 0.09 & 0.0 & 8.28 & 6.21 & 0.45 & 0.002 & 0.018 \\
\hline LJ7 & 81.37 & 0.07 & 0.0 & 10.41 & 6.74 & - & - & - \\
\hline
\end{tabular}




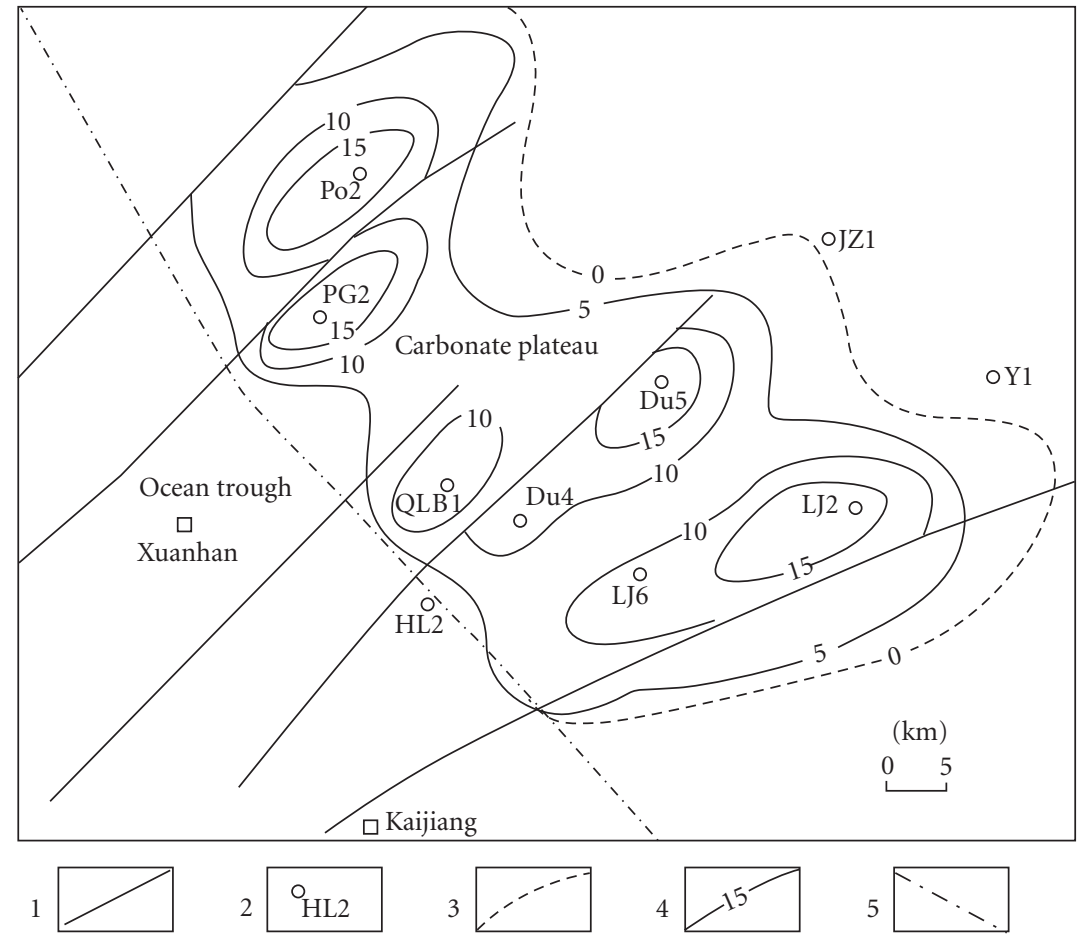

1. Fault
2. Well
3. Boundary of sedimentary facies
4. Content contour of solid bitumen in reservoir (\%)
5. Distribution area of solid bitumen in reservoir

FIGURE 6: Content contour of solid bitumen in reservoir of Feixianguan Formation in NE Sichaun Basin (modified from [22]).

(earliest Triassic). Multiple phases of tectonic deformation during the Yanshanian and Himalayan orogenies resulting in the development of the Dabashan foldbelt to the NE and the Eastern Sichuan foldbelt to the SE (Figures 5(a) and 5(b)). Carbonate platform strata have therefore been intensely deformed and the Feixianguan Formation was buried to depths of $3500 \mathrm{~m}$ to $6000 \mathrm{~m}$ [26].

Seven large natural gas accumulations have been discovered recently in the Lower Triassic Feixianguan Formation of the northeastern Sichuan Basin, located in the Luojiazhai, Dukouhe, Tieshanpo, Puguang, Jinzhuping, Huanglongchang, and Qilibei structures, respectively (Figure 5(c)). The gas pay zones are distributed under the regional caprock beds of the Lower Triassic Jialingjiang Formation, and almost all of the gas traps are associated with faults and fractures. Vertically, the highest-quality oolitic reservoirs are always within the $\mathrm{T}_{1} \mathrm{f}^{3}$ to $\mathrm{T}_{1} \mathrm{f}^{1}$ members. Laterally, reservoir qualities are comparable in four of the six structures, with an average $13-17 \%$ porosity. The only exception is observed in the Jinzhuping field where the average porosity is only $4.3 \%$. The solid bitumen that occurred commonly in oolitic reservoirs is the residual product resulting from crude oil cracking [13, 22, 27, 28].

Previous studies have proved that the gas pools have experienced oil reservoir phase and formed ultimately without any large-scale destruction or dissipation, and oil cracking occurred in a relatively closed geological system $[22,23]$. So the oolitic gas pools in NE Sichuan Basin are perfect area to extrapolate the resources prediction model established in our study.

5.2. Prediction of Oil Cracked Gas. As shown as Figure 6, a contour map was provided to show the content of solid bitumen in reservoir of Feixianguan Formation in NE Sichuan Basin [22]. According to the contours, weight average content of solid bitumen in reservoir is about $6.23 \%$, with distribution area of $700 \mathrm{~km}^{2}$. Firstly, the quality of solid bitumen in gas reservoir $\left(m_{b}\right)$ was estimated according to formulas

$$
m_{b}=\rho_{b} \times v_{b}, \quad v_{b}=S_{r} \times h_{r} \times b \%,
$$

where $\rho_{b}$ is density of solid bitumen in reservoir, general value adopted range in $1.36 \sim 1.98 \mathrm{~g} / \mathrm{cm}^{3}$ [29], $1.65 \mathrm{~g} / \mathrm{cm}^{3}$ was adopted here; $S_{r}$ is trap area, $700 \mathrm{~km}^{2}$ was adopted here; $h_{r}$ is efficient thickness of reservoir, average value $60 \mathrm{~m}$ was adopted; $b \%$ is volume percentage of solid bitumen in reservoir, average value $6.23 \%$ was adopted here; $v_{r}$ is efficient volume of reservoir; $v_{b}$ is volume of solid bitumen in 
reservoir. So the quality of solid bitumen $\left(m_{b}\right) 3.78 \times 10^{18} \mathrm{mg}$ was derived according to formulas (3).

When the $m_{b}$ value $\left(3.78 \times 10^{18} \mathrm{mg}\right)$ is inserted into formula (1), the volume of natural gas resources $v_{g}$ is equal to $6.84 \times 10^{12} \mathrm{~m}^{3}$, oil cracked gas is $97.5 \times 10^{8} \mathrm{~m}^{3} / \mathrm{km}^{2}$, and the paleo-oil reserve is $97 \times 10^{8} \mathrm{t}$.

The volume $\left(v_{g}\right)$ of natural gas resources was converted into the relative percentage according to

$$
\begin{aligned}
m_{g}=\frac{v_{g}}{22.4} \times( & \mathrm{M}_{1} \times \mathrm{CH}_{4} \%+\mathrm{M}_{2} \times \mathrm{C}_{2} \%+\cdots+\mathrm{M}_{i} \\
& \left.\times \mathrm{H}_{2} \mathrm{~S} \%+\mathrm{M}_{i+1} \times \mathrm{CO}_{2} \%\right),
\end{aligned}
$$

where $v_{g}$ is the natural gas resources $v_{g}$ (volume), value of $6.84 \times 10^{12} \mathrm{~m}^{3}, \mathrm{M}_{i}$ is mol mass of deferent composition (such as $\mathrm{CH}_{4}$, and $\mathrm{C}_{2} \mathrm{H}_{6}$ ) in natural gas, based on an average calculation of the composition data of natural gas given in Table 3 . The value of $m_{g}$ range in $5.78 \times 10^{18} \sim$ $6.29 \times 10^{18} \mathrm{mg}$ was acquired and put into formula (2). The value of $C m_{g}+C_{b}+C_{L}$ range in $0.957 \sim 0.985$, which is approximately equal to, and a little less than, 1 and indicates that the prediction value of natural gas resources is reliable in theory.

\section{Conclusions}

(1) The increase or decrease of gas, liquid, and solid matter residue in the process of crude oil pyrolysis in confined high-pressure system can be shown as the correlation among the yields of three pyrolysates. There is linear positive correlativity between the yields of total gas volume and pyrobitumen. The relationship between the yields of pyrobitumen and residual liquid hydrocarbons is a quadratic negative function correlation, the same as the relationship between total gas volume and residual liquid hydrocarbons. A prediction model based on solid bitumen in reservoir is suitable for the resource estimation of oil cracked gas. The verification formula is established on the basis of mass conservation. If the amount of solid bitumen in a reservoir is given, the resource of oil cracked gas and paleo-oil accumulation can be predicted accurately to some extent.

(2) The prediction model was extrapolated to the gas pools of Feixianguan formation in northeastern Sichuan basin. The prediction value of oil cracked resources is about $6.84 \times 10^{12} \mathrm{~m}^{3}$, and generation intensity of oil cracked gas is about $97.5 \times 10^{8} \mathrm{~m}^{3} / \mathrm{km}^{2}$, and the paleo-oil reserves is $97 \times 10^{8} \mathrm{t}$. The verifying value for this prediction $(0.957 \sim 0.985)$ is approximately equal to 1 , indicating that the model is reliable for application in the resource estimation of oil cracked gas.

(3) It is the first attempt to evaluate oil cracked gas resources through analyzing the increase or decrease of gas, liquid, and solid products in crude oil pyrolysis and the correlativity among the three yields.
Some new ideas are provided for the estimation of natural gas resources and the restoration of paleo-oil accumulations in the areas with high and over mature marine source rocks in south China. It is significant for the decision-making of natural gas exploration in China.

\section{Acknowledgments}

This paper was financially supported by the National Basic Research Program of China (no. 2007CB209500), the Youth Fund of Research Institute of Petroleum Exploration and Development, PetroChina (QY012201), and the science and technology innovation Fund of PetroChina (2010D-50060102). The authors are grateful to Professor Sun Yongge in Guangzhou Institute of Geochemistry for providing crude oil samples and Professor Liu Jinzhong, Liao Zewen, and Senior Engineer Xu An for their help in pyrolysis experiment.

\section{References}

[1] F. Behar, S. Kressmann, L. Rudkiewicz et al., "Experimental simulation in a confined system and kinetic modeling of kerogen and oil cracked," Organic Geochemistry, vol. 19, no. 1-3, pp. 173-189, 1992.

[2] F. Behar, M. Vandenbroucke, S. C. Teermann, P. G. Hatcher, C. Leblond, and O. Lerat, "Experimental simulation of gas generation from coals and a marine kerogen," Chemical Geology, vol. 126, no. 3-4, pp. 247-260, 1995.

[3] D. W. Waples, "The kinetics of in-reservoir oil destruction and gas formation: constraints from experimental and empirical data, and from thermodynamics," Organic Geochemistry, vol. 31, no. 6, pp. 553-575, 2000.

[4] F. Dominé, D. Dessort, and O. Brévart, "Towards a new method of geochemical kinetic modelling: implications for the stability of crude oils," Organic Geochemistry, vol. 28, no. 9-10, pp. 597-612, 1998.

[5] M. Vandenbroucke, F. Behar, and J. L. Rudkiewicz, "Kinetic modelling of petroleum formation and cracking: implications from the high pressure/high temperature Elgin field (UK, North Sea)," Organic Geochemistry, vol. 30, no. 9, pp. 11051125, 1999.

[6] N. Tsuzuki, N. Takeda, M. Suzuki, and K. Yokoi, "The kinetic modeling of oil cracking by hydrothermal pyrolysis experiments," International Journal of Coal Geology, vol. 39, no. 1-3, pp. 227-250, 1999.

[7] W. Z. Zhao, Z. Y. Wang, S. C. Zhang et al., "Oil cracked: an important way for highly efficient generationof gas from marine source rock kichen," Chinese Science Bulletin, vol. 50, no. 22, pp. 2628-2635, 2005.

[8] R. J. Hill, Y. Tang, and I. R. Kaplan, "Insights into oil cracking based on laboratory experiments," Organic Geochemistry, vol. 34, no. 12, pp. 1651-1672, 2003.

[9] W. Zhao, S. Zhang, F. Wang, J. Chen, Z. Xiao, and F. Song, "Gas accumulation from oil cracking in the eastern Tarim Basin: a case study of the YN2 gas field," Organic Geochemistry, vol. 36, no. 12, pp. 1602-1616, 2005.

[10] Z. J. Jin and J. C. Zhang, "Fundamental principles for petroleum resources assessments," Acta Petrolei Sinica, vol. 23, no. 1 , p. 19, 2002.

[11] X. Q. Pang, Z. J. Jin, Z. X. Jiang, and S. J. Zuo, "Evaluation of hydrocarbon resources of superimposed Basin and its 
significance," Petroleum Exploration and Development, vol. 29, no. 1, pp. 9-13, 2002.

[12] Y. Xiong, A. Geng, Y. Wang et al., "Kinetic simulating experiment on the secondary hydrocarbon generation of kerogen," Science in China D, vol. 45, no. 1, pp. 13-20, 2002.

[13] W. Z. Zhao, Z. Y. Wang, H. Q. He et al., "Gas generation mechanism of marine source rock in China," Science in China D, vol. 48, no. 4, pp. 441-453, 2005.

[14] D. I. G. Liang and J. P. Chen, "Oil-source correlations for high and over matured marine source rocks in South China," Petroleum Exploration and Development, vol. 32, no. 2, pp. 8 14, 2005.

[15] Y. S. Liao, "Some issues about evaluation on high-over matured gas source rocks," Petroleum Exploration and Development, vol. 32, no. 4, pp. 147-152, 2005.

[16] Y. Tang, J. K. Perry, P. D. Jenden, and M. Schoell, "Mathematical modeling of stable carbon isotope ratios in natural gases," Geochimica et Cosmochimica Acta, vol. 64, no. 15, pp. 26732687, 2000.

[17] H. Tian, Z. Wang, Z. Xiao, X. Li, and X. Xiao, "Oil cracking to gases: kinetic modeling and geological significance," Chinese Science Bulletin, vol. 51, no. 22, pp. 2763-2770, 2006.

[18] T. Wang, A. Geng, Y. Xiong, and X. Geng, "Mass balance calculation of the pyrolysates generated from marine crude oil: a prediction model of oil cracking gas resources based on solid bitumen in reservoir," Chinese Science Bulletin, vol. 52, no. 11, pp. 1532-1539, 2007.

[19] J. Z. Liu and Y. C. Tang, "A case of methane production prediction using kinetic experiment on hydrocarbon generation of kerogen," Chinese Science Bulletin, vol. 43, no. 11, pp. 11871191, 1998.

[20] X. Geng, A. Geng, Y. Xiong, J. Liu, H. Zhang, and Q. Zhao, "Kinetic study of the hydrocarbon generation from marine carbonate source rocks characterization of products of gas and liquid hydrocarbon," Chinese Science Bulletin, vol. 51, no. 23, pp. 2885-2891, 2006.

[21] J. J. Sweeney and A. K. Burnham, "Evaluation of a simple model of vitrinite reflectance based on chemical kinetics," American Association of Petroleum Geologists Bulletin, vol. 74, no. 10, pp. 1559-1570, 1990.

[22] W. Z. Zhao, Z. Y. Wang, Y. G. Wang et al., "Formation mechanism of highly effective gas pools in the feixianguan formation in the NE Sichuan Basin," Geological Review, vol. 52, no. 5, pp. 708-717, 2006.

[23] Y. Ma, "Generation mechanism of Puguang gas field in Sichuan Basin," Acta Petrolei Sinica, vol. 28, no. 2, pp. 9-21, 2007.

[24] W. L. Orr, "Geologic and geochemical controls on the distribution of hydrogen sulfide in natural gas," in Advances in Organic Geochemistry 1975, pp. 571-597, Empresa Nacional Adaro De Investigaciones Mineras, Madrid, Spain, 1977.

[25] G. Zhu, S. Zhang, Y. Liang et al., "Discussion on origins of the high- $\mathrm{H}_{2}$ S-bearing natural gas in China," Acta Geologica Sinica, vol. 79, no. 5, pp. 697-708, 2005.

[26] J. Li, Z. Xie, J. Dai, S. Zhang, G. Zhu, and Z. Liu, "Geochemistry and origin of sour gas accumulations in the northeastern Sichuan Basin, SW China," Organic Geochemistry, vol. 36, no. 12, pp. 1703-1716, 2005.

[27] D. Liu, X. Xiao, Y. Xiong et al., "Origin of natural sulphurbearing immiscible inclusions and $\mathrm{H}_{2} \mathrm{~S}$ in oolite gas reservoir, Eastern Sichuan," Science in China D, vol. 49, no. 3, pp. 242257, 2006.

[28] T. S. Wang, A. S. Geng, Y. G. Sun et al., "Geochemical characteristics of solid bitumen in reservoir and their implication for the origin of natural gas of feixianguan formation in Northeastern Sichuan Basin," Acta Sedimentologica Sinica, vol. 26, no. 2, pp. 340-348, 2008.

[29] H. Zhang, C. Fang, X. Gao et al., Petroleum Geology, Petroleum Industry Press, Bejing, China, 1999. 

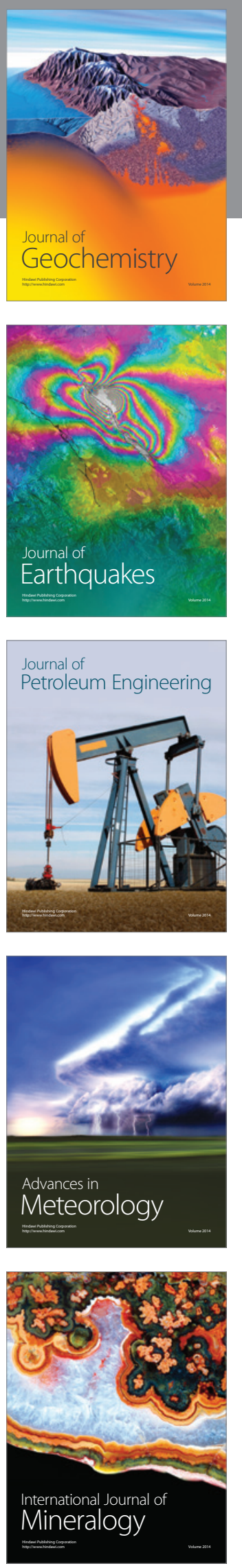
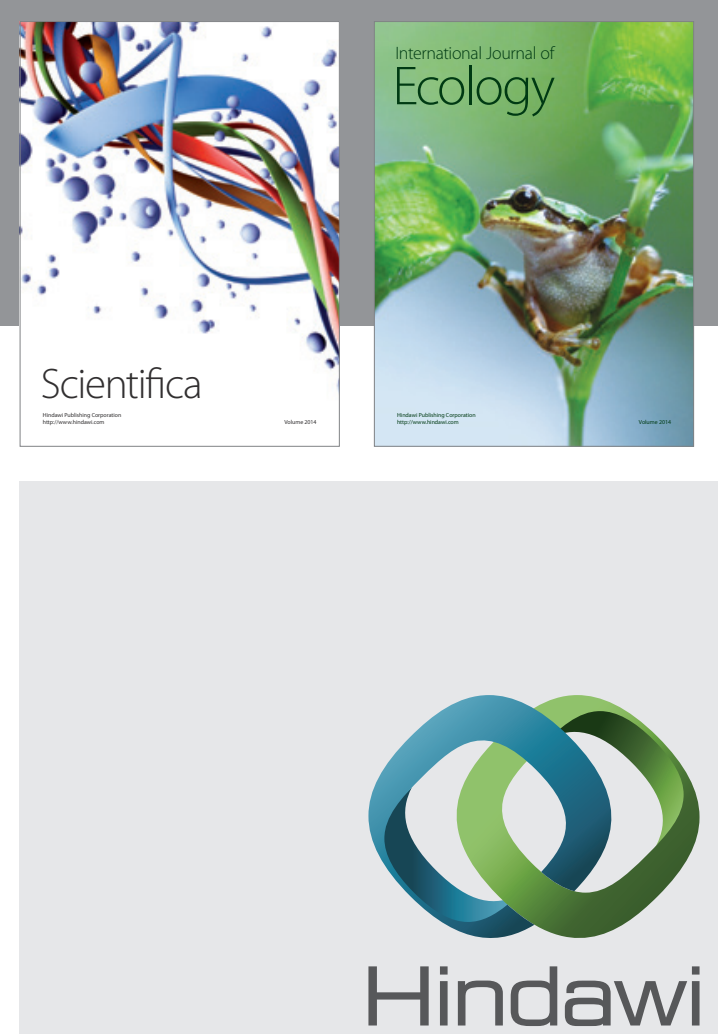

Submit your manuscripts at http://www.hindawi.com
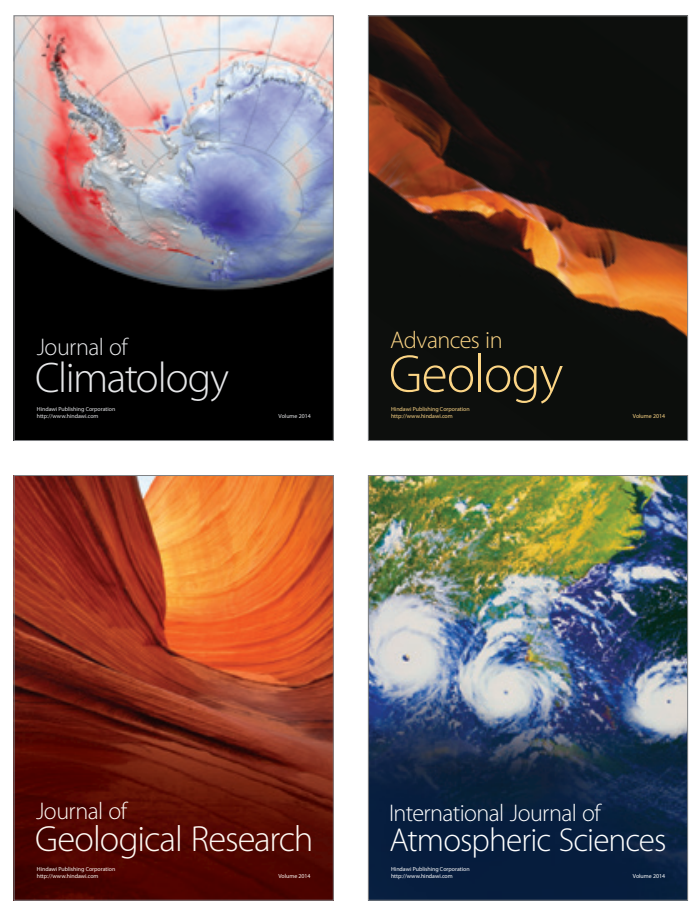
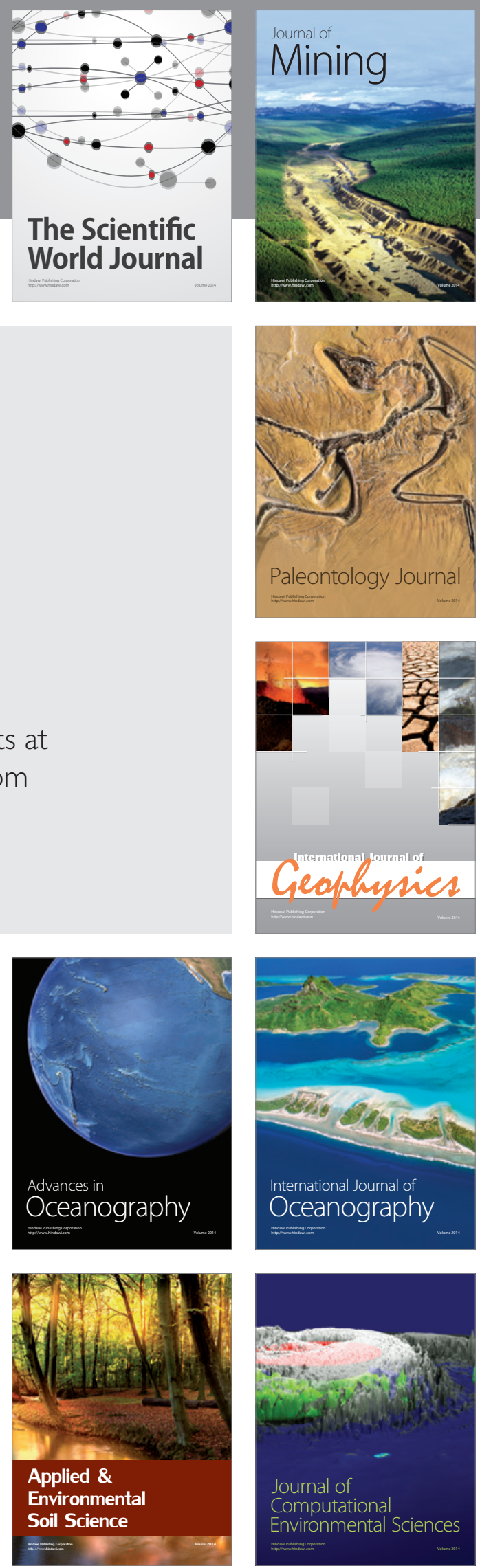